\title{
Working
}

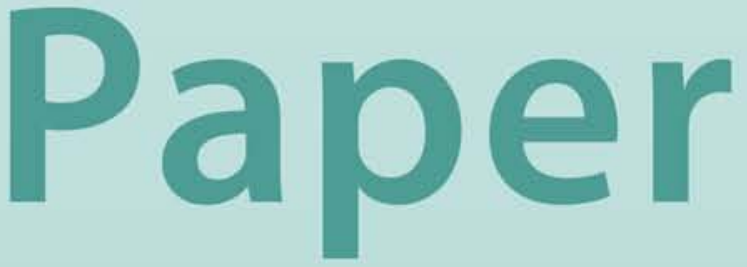


Monetary and Macroprudential Policy Rules in a Model with House Price Booms

\author{
Prakash Kannan, Pau Rabanal, \\ and Alasdair Scott
}




\title{
IMF Working Paper
}

\author{
Research Department
}

\section{Monetary and Macroprudential Policy Rules in a Model with House Price Booms}

\author{
Prepared by Prakash Kannan, Pau Rabanal, and Alasdair Scott ${ }^{1}$
}

Authorized for distribution by Jörg Decressin

November 2009

\begin{abstract}
This Working Paper should not be reported as representing the views of the IMF. The views expressed in this Working Paper are those of the author(s) and do not necessarily represent those of the IMF or IMF policy. Working Papers describe research in progress by the author(s) and are published to elicit comments and to further debate.

We argue that a stronger emphasis on macrofinancial risk could provide stabilization benefits. Simulations results suggest that strong monetary reactions to accelerator mechanisms that push up credit growth and asset prices could help macroeconomic stability. In addition, using a macroprudential instrument designed specifically to dampen credit market cycles would also be useful. But invariant and rigid policy responses raise the risk of policy errors that could lower, not raise, macroeconomic stability. Hence, discretion would be required.
\end{abstract}

JEL Classification Numbers:E52, E61

Keywords: house prices, monetary policy, macroprudential

Author's E-Mail Address:pkannan@imf.org prabanal@imf.org, ascott@,imf.org,

\footnotetext{
${ }^{1}$ The authors would like to thank Olivier Blanchard, Charles Collyns, Jörg Decressin, Antonio Fatás, Jordi Galí, David Romer, and seminar participants at the Bank of Canada, Bank of England, Board of Governors of the Federal Reserve, IMF, and Her Majesty's Treasury for thoughtful discussions and comments. The remaining errors are our own.
} 


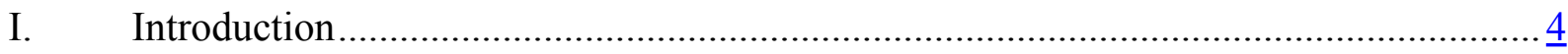

II. A Model for Analyzing House Price Booms ................................................... 5

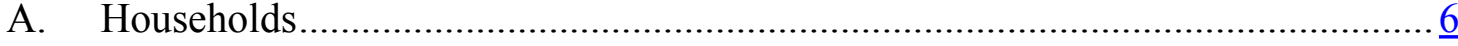

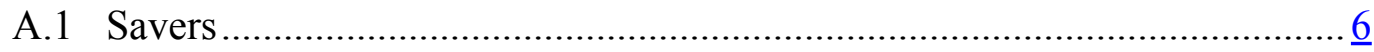

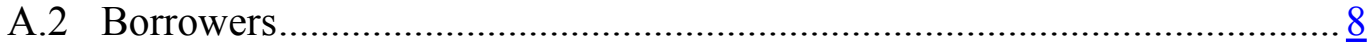

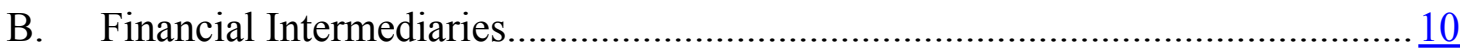

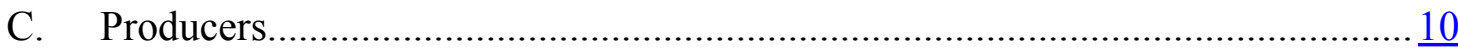

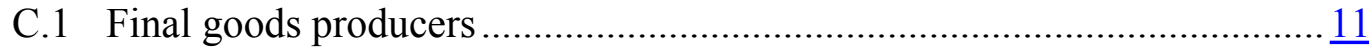

C.2 Intermediate goods producers .................................................... 11

D. Closing the Model: Market Clearing Conditions .......................................... 12

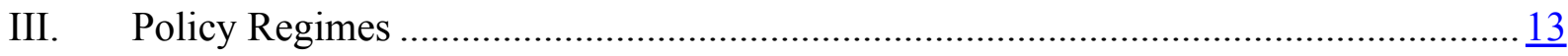

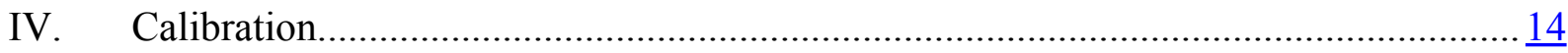

V. Simulation Results ............................................................................ 15

A. The Performance of Policy Rules in Reaction to Financial Shocks .................. 15

B. The Performance of Policy Rules in Reaction to Productivity Shocks .............. 17

C. Policy Rules with Multiple Shocks.............................................................. 18

VI. Robustness of the Results ............................................................................. 19

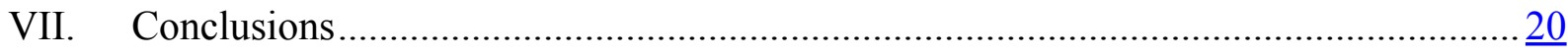

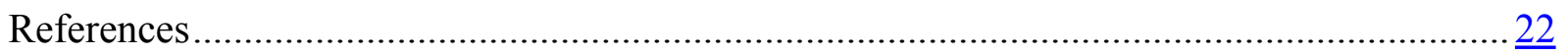

Tables

1. Parameter Values ........................................................................................ 24

2. Parameters of Policy Rules in Reaction to Financial Shocks ................................... 25

3. Performance of Policy Rules in Reaction to Financial Shocks................................. $\underline{26}$

4. Parameters of Policy Rules in Reaction to Productivity Shocks ............................... 27

5. Performance of Policy Rules in Reaction to Productivity Shocks.............................. 28

6. Sensitivity of Parameters of Policy Rules Optimized to Financial Shocks to Changes in Key Parameters .......................................................................... 29

7. Sensitivity of Parameters of Policy Rules Optimized to Productivity Shocks to Changes in Key Parameters ................................................................ 


\section{Figures}

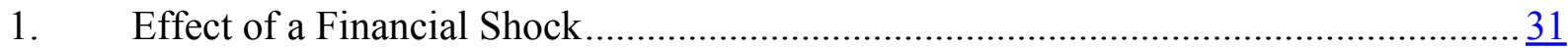

2. Effect of a Productivity Shock ………………….............................................

3. Optimal Weight on Nominal Credit in the Macroprudential Rule ………………....... 33

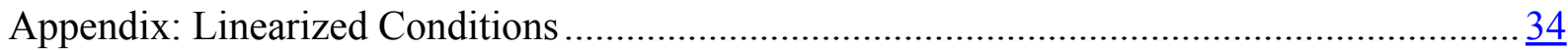




\section{Introduction}

Empirical work has found a number of variables that are often associated with future asset price busts, such as credit, the share of residential investment in GDP, and current account balances. ${ }^{2}$ Those same variables do reasonably well in explaining the differences across countries in house price rises leading up to the current crisis. ${ }^{3}$ Such evidence suggests that if central bankers wish to mitigate damaging asset price boom-bust cycles, they should consider reacting to such variables rather than focusing mainly on inflation and output. However, there are still a number of important questions to be addressed in assessing the appropriate policy responses:

- What are the potential gains from reacting to signs of emerging financial vulnerability?

- Is monetary policy the appropriate tool for reacting to such indicators, or should other policies be used?

- What are the trade-offs between focusing policy on stabilizing output and CPI inflation and attempting to reduce the risk of asset price crashes?

This paper addresses these questions with simulations conducted using a model economy that has some of the key features relevant for examining the potential role of monetary policy in mitigating the effects of asset price booms. It makes the case that putting more emphasis on macrofinancial risk could provide stabilization benefits. The results from the simulations suggest that a stronger monetary reaction to signs of overheating or of a credit or asset price bubble could help counter accelerator mechanisms that push up credit growth and asset prices. In addition, using a macroprudential instrument designed specifically to dampen credit market cycles would also be useful. But expectations should be realistic about what can be achieved with such an approach. In particular, it is often difficult to accurately identify the source of the shock driving observed house price booms. Invariant and rigid policy responses raise the risk of policy errors that could lower, not raise, macroeconomic stability. Hence, discretion would need to be applied to the use of monetary and macroprudential policies in attempting to mitigate macrofinancial risks.

How do these conclusions compare with those from other studies? There is a vast literature on monetary policy and asset prices. The debate persists over whether central banks should react directly to asset prices. Two well-known examples are Bernanke and Gertler (2001), who conclude that there is no role for asset prices in monetary policy rules, and Cecchetti et al.

${ }^{2}$ See, inter alia, Borio and Lowe (2004) and Kannan et al. (2009).

${ }^{3}$ See IMF (2009). 
(2000), who argue that central banks should react to asset prices. Increasingly, the literature suggests gains from including asset prices in monetary policy rules. ${ }^{4}$ Gray et al. (2009) find a role for a financial stability indicator in the monetary rule. Two aspects differentiate this paper. First, we distinguish between gains that arise from adding indicators of financial stress such as excessive credit growth to standard but second best monetary policy rules and those from including the same indicators in fully optimized rules. Second, as far as we know, this is the first time the coordination of monetary and macroprudential rules has been formally evaluated using a macroeconomic model of this type. ${ }^{5}$

The paper is structured as follows. Section 2 contains a description of the model and Section 3 a description of the policy regimes evaluated in the simulations. Section 4 summarizes the model's calibration. The results of simulation experiments are presented in Section 5. In the following section, sensitivity analysis is performed. The final section concludes. An appendix details the linearized conditions for the model.

\section{A Model for Analyzing House Price Booms}

The model used in this paper has a number of modifications to the standard New Keynesian model (Galí, 2009) with regard to the characterization of households and financial markets, which create a special role for asset prices. Because housing wealth is generally more important for most households than equities, and because house purchases typically require debt financing, we concentrate on the role of housing. ${ }^{6}$ First, households make choices about how much to invest in housing, as well as how much to consume in nondurable goods. Housing is an asset that provides services and is the main vehicle for accumulating wealth in this economy. Second, we make a distinction between borrowers and lenders, creating conditions for leverage. Third, the lending rate is modeled as a spread over the policy rate that depends on loan-to-value ratios, the markup charged over funding (policy) rates, and, in some cases discussed below, a macroprudential instrument. Hence, lending rates can change for a number of reasons: for example, a rise in house prices will raise market valuations of borrowers' collateral, lowering the average loan-to-value ratio, and will therefore lead to a fall in lending rates even if monetary policy has not eased. Credit market conditions can change — because of, say, changes in perceptions of risk or competitiveness in lending — which

\footnotetext{
${ }^{4}$ Recent examples include Christiano et al. (2007).

${ }^{5}$ Gruss and Sgherri (2009) study the welfare implications of procyclical loan-to-value ratios in a two-country model. However, because the model does not have a nominal side, the reaction of monetary policy cannot be addressed.

${ }^{6}$ For a model that considers the monetary policy implications of stock price fluctuations, see Christiano and others (2007).
} 
could lead banks to adjust their markups and therefore alter the lending spread. Both of these mechanisms help accelerate a rise in residential investment, nondurable consumption, and prices. ${ }^{7}$ In some simulations, policy makers can affect spreads directly, using a macroprudential tool, in addition to influencing lending rates via policy rates.

In other aspects, the model has conventional New Keynesian foundations. The theoretical framework consists of a general equilibrium two-sector model, durables and non-durables, where each sector operates under monopolistic competition and nominal rigidities. Prices in both sectors are sticky in the short run, as in Calvo (1983). Consumption and residential investment adjust slowly due, respectively, to habit formation and adjustment costs. It is costly for workers to shift from working on the production of consumption goods to building houses, and vice versa. For simplicity, there is no capital used in production and the economy is closed.

\section{A. Households}

Households obtain utility from consuming the stock of durables and the flow of nondurables. There are two types of households in this economy, borrowers and savers. Borrowers are assumed to be more impatient than savers, by having a smaller discount factor. In equilibrium, savers will provide financing to borrowers. A fraction $\lambda$ of households are considered to be savers, the remaining fraction $1-\lambda$ are borrowers.

\section{A.1 Savers}

Each saver $j \in[0, \lambda]$ maximizes the following utility function:

$$
E_{0}\left\{\sum_{t=0}^{\infty} \beta^{t}\left[\gamma \log \left(C_{t}^{j}-\varepsilon C_{t-1}\right)+(1-\gamma) \log \left(D_{t}^{j}\right)-\frac{\left(L_{t}^{j}\right)^{1+\varphi}}{1+\varphi}\right]\right\},
$$

where $C_{t}^{j}$ denotes consumption of non-durable goods, $D_{t}^{j}$ denotes consumption of durable goods, and $L_{t}^{i, j}$ denotes hours worked by household $j$ in each sector $i=C, D$. $\beta$ is the discount factor. Households form external habits in consumption, as in Smets and Wouters (2003) and Iacoviello and Neri (2009), with $\varepsilon$ denoting the importance of the habit stock, which is last period's aggregate consumption $\left(C_{t-1}\right)$. Finally, following Iacoviello and Neri

\footnotetext{
${ }^{7}$ These features draw on elements of models by Aoki et al. (2004), Curdia and Woodford (2009), Iacoviello (2005), and Monacelli (2009). The accelerator mechanism goes back to Bernanke et al. (BGG, 1998); unlike BGG, the accelerator in this model works through housing finance rather than firms' capital.
} 
(2009), we assume that there is imperfect substitutability of labor supply across sectors, such that the labor disutility index can be written as

$$
L_{t}^{j}=\left[\alpha^{-\iota_{L}}\left(L_{t}^{C, j}\right)^{1+\iota_{L}}+(1-\alpha)^{-\iota_{L}}\left(L_{t}^{D, j}\right)^{1+\iota_{L}}\right]^{\frac{1}{1+\iota_{L}}} \text {, where } \iota_{L}>0,
$$

and $\alpha$ is the economic size of each sector. This imperfect substitutability implies that reallocating labor across sectors following a shock is costly. Note that when $\iota_{L}=0$ the aggregator is linear in hours worked in each sector, so there are no costs of switching from working in one sector to the other. This cost helps the model to explain positive comovement of real variables in both sectors in response to aggregate shocks.

The budget constraint of the savers, in nominal terms, is given by

$$
P_{t}^{C} C_{t}^{j}+P_{t}^{D} I_{t}^{j}+B_{t}^{j} \leq R_{t-1} B_{t-1}^{j}+W_{t}^{C} L_{t}^{C, j}+W_{t}^{D} L_{t}^{D, j}+\Pi_{t}^{j},
$$

where $P_{t}^{C}$ and $P_{t}^{D}$ are the price indices of durable and non-durable goods, respectively, $W_{t}^{i}$ is the nominal wage in each sector $i=C, D$, and $B_{t}^{j}$ denotes saving instruments (such as debt instruments or deposits) that borrowers place in banks, at a gross interest rate of $R_{t} . \Pi_{t}^{j}$ denotes nominal profits from intermediate goods producing firms and banks, which are ultimately owned by savers.

$I_{t}^{j}$ denotes residential investment. We assume that the law of motion of the housing stock evolves as follows:

$$
D_{t}^{j}=(1-\delta) D_{t-1}^{j}+\left[1-S\left(\frac{I_{t}^{j}}{I_{t-1}^{j}}\right)\right] I_{t}^{j},
$$

where $\delta$ denotes the rate of depreciation of the housing stock and, following Christiano, Eichenbaum, and Evans (2005), we introduce an adjustment cost function, $S($.$) , which is$ convex (i.e. $S^{\prime \prime}()>0$ ). In the steady state $\bar{S}=\bar{S}^{\prime}=0$ and $\bar{S}^{\prime \prime}>0$. The aim of introducing this cost is to allow for the possibility that the model can generate hump-shaped responses of residential investment to shocks.

The first order conditions to the household maximization problem are given by the following expressions, where $\lambda_{t}$ is the Lagrange multiplier associated with the budget constraint, and $\mu_{t}$ is the Lagrange multiplier associated with equation (4): ${ }^{8}$

$$
U_{C_{t}}=\lambda_{t} P_{t}^{C}
$$

\footnotetext{
${ }^{8}$ Since all savers behave the same way, we drop the $j$ subscripts in what follows.
} 


$$
\begin{gathered}
U_{D_{t}}=\mu_{t}-\beta(1-\delta) E_{t} \mu_{t+1} \\
\lambda_{t} P_{t}^{D}=\mu_{t}\left\{1-S\left(\frac{I_{t}}{I_{t-1}}\right)-S^{\prime}\left(\frac{I_{t}}{I_{t-1}}\right) \frac{I_{t}}{I_{t-1}}\right\}+\beta E_{t} \mu_{t+1}\left[S^{\prime}\left(\frac{I_{t+1}}{I_{t}}\right)\left(\frac{I_{t+1}}{I_{t}}\right)^{2}\right]
\end{gathered}
$$

Absent adjustment costs to residential investment (i.e. $S=0$ ), these three equations can be reduced to the following condition:

$$
\frac{P_{t}^{D}}{P_{t}^{C}}=\frac{1-\gamma}{\gamma} \frac{\xi_{t}^{D}\left(C_{t}-\varepsilon C_{t-1}\right)}{D_{t}}+\beta(1-\delta) E_{t}\left[\left(\frac{C_{t}-\varepsilon C_{t-1}}{C_{t+1}-\varepsilon C_{t}}\right) \frac{P_{t+1}^{D}}{P_{t+1}^{C}}\right]
$$

Note that if the durable good is in fact completely non-durable (i.e. $\delta=1$ ), this condition simply equates the marginal utilities of consumption to relative prices. Since the durable good has a residual value the following period, this induces the extra-term of holding an additional unit of the durable good.

The Euler equation for the consumption of non-durable goods with habits is standard:

$$
1=\beta R_{t} E_{t}\left[\frac{P_{t}^{C}}{P_{t+1}^{C}}\left(\frac{C_{t}-\varepsilon C_{t-1}}{C_{t+1}-\varepsilon C_{t}}\right)\right]
$$

and the labor supply conditions to both sectors are given by

$$
L_{t}^{\varphi-\iota_{L}} \alpha^{-\iota_{L}}\left(L_{t}^{C}\right)^{\iota_{L}}=\left(\frac{\gamma}{C_{t}-\varepsilon C_{t-1}}\right) \frac{W_{t}^{C}}{P_{t}^{C}}
$$

and

$$
L_{t}^{\varphi-\iota_{L}}(1-\alpha)^{-\iota_{L}}\left(L_{t}^{D}\right)^{\iota_{L}}=\left(\frac{\gamma}{C_{t}-\varepsilon C_{t-1}}\right) \frac{W_{t}^{D}}{P_{t}^{C}}
$$

\section{A.2 Borrowers}

Each borrower $j \in[\lambda, 1]$ maximizes the following utility function:

$$
E_{0}\left\{\sum_{t=0}^{\infty} \beta^{B, t}\left[\gamma \log \left(C_{t}^{B, j}-\varepsilon C_{t-1}^{B}\right)+(1-\gamma) \xi_{t}^{D} \log \left(D_{t}^{B, j}\right)-\frac{\left(L_{t}^{B, j}\right)^{1+\varphi}}{1+\varphi}\right]\right\}
$$


in which all variables with a $B$ superscript are the borrowers' analog to the savers' variables above. $\beta^{B}<\beta$ is the discount factor of the borrowers; it is assumed that borrowers are more impatient than savers. Their budget constraint in nominal terms is given by

$$
P_{t}^{C} C_{t}^{B, j}+P_{t}^{D} I_{t}^{B, j}+R_{t-1}^{L} B_{t-1}^{B, j} \leq B_{t}^{B, j}+W_{t}^{C} L_{t}^{C, B, j}+W_{t}^{D} L_{t}^{D, B, j}
$$

Borrowers can obtain loans from banks at a lending rate of $R_{t}^{L}$.

We assume that the functional forms for aggregate labor supply, $L_{t}^{B, j}$, and for the law of motion of housing stock, $D_{t}^{B, j}$, are the same as in the case of savers. Hence, the first order conditions for the borrower households are given by

$$
\begin{gathered}
U_{C_{t}^{B}}=\lambda_{t}^{B} P_{t}^{C}, \\
U_{D_{t}^{B}}=\mu_{t}^{B}-\beta^{B}(1-\delta) E_{t} \mu_{t+1}^{B},
\end{gathered}
$$

and

$$
\lambda_{t}^{B} P_{t}^{D}=\mu_{t}^{B}\left\{1-S\left(\frac{I_{t}^{B}}{I_{t-1}^{B}}\right)-S^{\prime}\left(\frac{I_{t}^{B}}{I_{t-1}^{B}}\right) \frac{I_{t}^{B}}{I_{t-1}^{B}}\right\}+\beta^{B} E_{t} \mu_{t+1}^{B}\left[S^{\prime}\left(\frac{I_{t+1}^{B}}{I_{t}^{B}}\right)\left(\frac{I_{t+1}^{B}}{I_{t}^{B}}\right)^{2}\right]
$$

The Euler equation for borrowers is

$$
\lambda_{t}^{B}=\beta^{B} R_{t}^{L} E_{t} \lambda_{t+1}^{B}
$$

Substituting for the expression of marginal utility we obtain the consumption Euler equation for borrowers:

$$
1=\beta^{B} R_{t}^{L} E_{t}\left[\frac{P_{t}^{C}}{P_{t+1}^{C}}\left(\frac{C_{t}^{B}-\varepsilon C_{t-1}^{B}}{C_{t+1}^{B}-\varepsilon C_{t}^{B}}\right)\right],
$$

while the corresponding labor supply conditions to both sectors are given by

$$
\left(L_{t}^{B}\right)^{\varphi-\iota_{L}} \alpha^{-\iota_{L}}\left(L_{t}^{B, C}\right)^{\iota_{L}}=\left(\frac{\gamma}{C_{t}^{B}-\varepsilon C_{t-1}^{B}}\right) \frac{W_{t}^{C}}{P_{t}^{C}}
$$

and

$$
\left(L_{t}^{B}\right)^{\varphi-\iota_{L}}(1-\alpha)^{-\iota_{L}}\left(L_{t}^{B, D}\right)^{\iota_{L}}=\left(\frac{\gamma}{C_{t}^{B}-\varepsilon C_{t-1}^{B}}\right) \frac{W_{t}^{D}}{P_{t}^{C}}
$$




\section{B. Financial Intermediaries}

We assume that savers cannot lend to borrowers directly-we introduce financial intermediaries that take deposits from savers and lend them to borrowers, charging a spread that depends on the net worth of borrowers. The spread of the bank lending rate $\left(R_{t}^{L}\right)$ over the deposit/risk free rate $\left(R_{t}\right)$ is a function of a time-varying mark-up; borrowers' aggregate net worth, following the financial accelerator idea of Bernanke et al. (1998) and Aoki et al. (2004); and a macroprudential instrument:

$$
R_{t}^{L}=v_{t} R_{t} F\left(B_{t}^{B} / P_{t}^{D} D_{t}^{B}\right) \tau_{t}
$$

More precisely:

- $v_{t}$ is a financial shock that follows an $\mathrm{AR}(1)$ process in logs. In the steady state, its mean value $v$ denotes the markup in the banking sector. Changes in $v_{t}$ can be thought of as a reduction in the margin banks charge over funding costs, caused by an increase in competition and a quest for market share or by a reduction in perceived lending risk.

- $F$ is a function of the net worth of borrowers, $B_{t}^{B} / P_{t}^{D} D_{t}^{B}$. We assume that $F^{\prime}()>0, F^{\prime \prime}()>0$. Also, we assume that $F(1-\chi)=0$. One can interpret the fraction $\chi$ as a down-payment rate, or one minus the loan-to-value ratio. ${ }^{9}$ Increased housing prices will lead to an improvement of the net worth position of borrowers, which will allow them to borrow at a lower rate.

- $\tau_{t}$ is a macroprudential instrument that allows the central bank to affect market rates by imposing additional capital requirements or provisions whenever credit growth is above its steady-state value. Below, we discuss specific functional forms for this policy tool.

\section{Producers}

There is a continuum of producers that supply imperfectly substitutable intermediate goods and a continuum of final goods producers in each of the two sectors that operate under perfect competition and flexible prices.

\footnotetext{
${ }^{9}$ The case that Monacelli (2009) and Iacoviello (2005) analyze is $F()=.\infty$ whenever $B_{t}^{B}$ differs from $(1-\chi) P_{t}^{D} D_{t}^{B}$. That is, the constraint holds with equality and the penalty of deviating from it makes it impossible that anyone would want to do so. Here, we allow borrowers to go beyond the loan-to-value ratio but at a higher lending rate.
} 


\section{C.1 Final goods producers}

In the durable sector, final goods producers purchase intermediate goods producers and aggregate them according to the following production function:

$$
Y_{t}^{D} \equiv\left[\int_{0}^{1} Y_{t}^{D}(i)^{\frac{\sigma_{D}-1}{\sigma_{D}}} d i\right]^{\frac{\sigma_{D}}{\sigma_{D}-1}} .
$$

Profit maximization delivers the following demand for individual intermediate non-durable goods:

$$
Y_{t}^{D}(i)=\left(\frac{P_{t}^{D}(i)}{P_{t}^{D}}\right)^{-\sigma_{D}} Y_{t}^{D}
$$

where the price level is given by imposing the zero-profit condition:

$$
P_{t}^{D} \equiv\left\{\int_{0}^{1}\left[P_{t}^{D}(i)\right]^{1-\sigma_{D}} d i\right\}^{\frac{1}{1-\sigma_{D}}}
$$

In the non-durable goods sector, expressions are similar.

\section{C.2 Intermediate goods producers}

Intermediate goods producers face a Calvo-type restriction when setting their prices. In each period, a fraction $1-\theta_{i}$ in each sector $(i=C, D)$ receive a signal to reset their price optimally. In addition, a fraction $\varphi_{i}$ index their price to last period's sectoral inflation rate whenever they are not allowed to reset their price.

Intermediate goods in both sectors are produced with labor only:

$$
\begin{aligned}
& Y_{t}^{C}(i)=A_{t}^{C} L_{t}^{C}(i), \text { for all } i \in[0,1] \\
& Y_{t}^{D}(i)=A_{t}^{D} L_{t}^{D}(i), \text { for all } i \in[0,1] .
\end{aligned}
$$

Note that in each sector, the production function is hit by sector specific technology shocks, each of which follows an AR(1) in logs. In the simulation part, we will only focus on productivity shocks in the nondurable sector.

In the remaining part of this subsection, we work out the conditions for the home country firms pricing decisions. In each sector, cost minimization implies that the real marginal cost of 
production is

$$
M C_{t}^{x}=\frac{W_{t}^{x} / P_{t}^{x}}{A_{t}^{x}}, x=C, D .
$$

Note that even though labor is the only production input, labor costs may differ across sectors because of imperfect labor substitutability, which can lead to different real (product) wages. Also, real unit labor costs can differ because of the sector-specific technology shocks.

Firms in the durable sector face the following maximization problem:

$$
\max _{P_{t}^{D}(i)} E_{t} \sum_{k=0}^{\infty} \theta_{D}^{k} \Lambda_{t, t+k}\left\{\left[\frac{P_{t}^{D}(i)\left(\frac{P_{t+k-1}^{D}}{P_{t-1}^{D}}\right)^{\varphi_{D}}}{P_{t+k}^{D}}-M C_{t+k}^{D}\right] Y_{t+k}^{D}(i)\right\}
$$

subject to future demand

$$
Y_{t+k}^{D}(i)=\left[\frac{P_{t}^{D}(i)}{P_{t+k}^{D}}\left(\frac{P_{t+k-1}^{D}}{P_{t-1}^{D}}\right)^{\varphi_{D}}\right]^{-\sigma_{D}} Y_{t+k}^{D},
$$

where $\Lambda_{t, t+k}=\beta^{k} \frac{\lambda_{t+k}}{\lambda_{t}}$ is the stochastic discount factor. The optimal choice is given by

$$
\frac{\hat{P}_{t}^{D}}{P_{t}^{D}}=\frac{\sigma_{D}}{\left(\sigma_{D}-1\right)} E_{t}\left\{\frac{\sum_{k=0}^{\infty} \beta^{k} \theta_{D}^{k} \lambda_{t+k}\left(\prod_{s=1}^{k} \frac{\left(\Pi_{t+s-1}^{D}\right)^{\varphi_{D}}}{\Pi_{t+s}^{D}}\right)^{-\sigma_{D}} M C_{t+k}^{D} Y_{t+k}^{D}}{\sum_{k=0}^{\infty} \beta^{k} \theta_{D}^{k} \lambda_{t+k}\left(\prod_{s=1}^{k} \frac{\left(\Pi_{t+s-1}^{D}\right)^{\varphi_{D}}}{\Pi_{t+s}^{D}}\right)^{1-\sigma_{D}} Y_{t+k}^{D}}\right\}
$$

Given the assumptions about Calvo pricing, the evolution of the price level is

$$
P_{t}^{D}=\left\{\theta_{D}\left[P_{t-1}^{D}\left(\Pi_{t-1}^{D}\right)^{\varphi_{D}}\right]^{1-\sigma_{D}}+\left(1-\theta_{D}\right)\left(\hat{P}_{t}^{D}\right)^{1-\sigma_{D}}\right\}^{\frac{1}{1-\sigma_{D}}}
$$

Firms in the non-durable sector face a similar maximization problem, and hence the optimal price and the evolution of the price level have similar expressions, with the appropriate change of notation.

\section{Closing the Model: Market Clearing Conditions}

For each intermediate good, supply equals demand. We write the market clearing conditions in terms of aggregate quantities. Total production in the non-durable sector is equal to total consumption: 


$$
Y_{t}^{C}=\lambda C_{t}+(1-\lambda) C_{t}^{B}
$$

Total durable production equals aggregate residential investment:

$$
Y_{t}^{D}=\lambda I_{t}+(1-\lambda) I_{t}^{B}
$$

Aggregate real GDP is

$$
Y_{t}=\left(P_{t}^{C} Y_{t}^{C}+P_{t}^{D} Y_{t}^{D}\right) / P_{t}
$$

where $P_{t}$ is the GDP deflator. Total hours worked equals labor supply in each sector:

$$
\begin{aligned}
\int_{0}^{1} L_{t}^{C}(i) d i & =\int_{0}^{\lambda} L_{t}^{C, j} d j+\int_{\lambda}^{1} L_{t}^{C, B, j} d j \\
\int_{0}^{1} L_{t}^{D}(i) d i & =\int_{0}^{\lambda} L_{t}^{D, j} d j+\int_{\lambda}^{1} L_{t}^{D, B, j} d j .
\end{aligned}
$$

Market clearing in the deposit/lending market is

$$
\lambda B_{t}+(1-\lambda) B_{t}^{B}=0
$$

In the following section we discuss the role of monetary and financial policies.

\section{Policy Regimes}

In this model, two types of policy interventions are possible. First, due to the presence of sticky prices, monetary policy has real effects. Second, because of the presence of financial frictions, we assume that policy makers can affect the market lending rate by imposing additional capital requirements or additional provisioning when credit growth is above its steady-state value-the $\tau_{t}$ term in equation (18).

Given these two instruments, we model four policy regimes used in the experiments that follow. The baseline policy regime is a Taylor rule, specified with a weight of 1.5 on CPI inflation and 0.5 on the output gap. Let $\bar{\Pi}^{C}$ be the steady-state level of inflation and $Y_{t}^{*}$ the level of potential output, which is defined as the dynamics of aggregate real GDP when the economy does not have nominal or financial rigidities, and all agents are homogeneous. We allow for interest rate inertia, and the variables on the r.h.s. of all rules are lagged. ${ }^{10}$ The

\footnotetext{
${ }^{10}$ These lags are introduced on the grounds that, in real life, the policy maker only has data for the output gap and inflation after some delay. Data for money aggregates and credit are available more readily. Including contemporaneous credit in the augmented Taylor and macroprudential rules would increase the value of credit as an indicator, and therefore bias the conclusions reached here in favor of extended frameworks. To avoid this,
} 
Taylor rule regime is therefore described by the policy rule

$$
R_{t}=\left[\bar{R}\left(\frac{P_{t-1}^{C} / P_{t-2}^{C}}{\bar{\Pi}^{C}}\right)^{\gamma_{\Pi}}\left(\frac{Y_{t-1}}{Y_{t-1}^{*}}\right)^{\gamma_{y}}\right]^{1-\gamma_{R}}\left(R_{t-1}\right)^{\gamma_{R}}
$$

With that benchmark, we investigate gains to be achieved by incorporating information from indicators of potential financial vulnerability. Hence, the second regime is implemented as a Taylor-type rule in which monetary policy also reacts to the growth rate of nominal credit, $\left(\frac{B_{t-1}^{B}}{B_{t-2}^{B}} \frac{P_{t-1}}{P_{t-2}}\right)$, in addition to CPI inflation and the output gap. Hence, the augmented Taylor rule regime has the form:

$$
R_{t}=\left[\bar{R}\left(\frac{P_{t-1}^{C} / P_{t-2}^{C}}{\bar{\Pi}^{C}}\right)^{\gamma_{\Pi}}\left(\frac{Y_{t-1}}{Y_{t-1}^{*}}\right)^{\gamma_{y}}\left(\frac{B_{t-1}^{B}}{B_{t-2}^{B}} \frac{P_{t-1}}{P_{t-2}}\right)^{\gamma_{b}}\right]^{1-\gamma_{R}}\left(R_{t-1}\right)^{\gamma_{R}}
$$

The macroprudential rule specifies the reaction of a macroprudential instrument to lagged nominal credit changes (the same variable as in the augmented Taylor rule (32)):

$$
\tau_{t}=\tau\left(\frac{B_{t-1}^{B}}{B_{t-2}^{B}} \frac{P_{t-1}}{P_{t-2}}\right) .
$$

The macroprudential instrument affects lending rates-we assume that policy makers can directly offset, to some degree, fluctuations in spreads caused by the changes in collateral values and financial shocks described above (see equation 18). This can be thought of as a simple short cut that mimics the effects of, say, regulations that require banks to set aside more capital as asset prices rise, hence raising the margin that banks have to charge over funding costs (the policy rate). Combining the macroprudential rule with the augmented Taylor rule produces the augmented Taylor plus macroprudential regime.

The final policy regime is a variation on the third, in which the weight on each variable is determined by an optimization procedure that seeks the best response to the particular shock, by optimizing over $\gamma_{\Pi}, \gamma_{y}, \gamma_{b}$, and $\tau$. This will be termed the optimized augmented Taylor plus macroprudential regime.

\section{Calibration}

The calibration of the model is summarized in Table 1. Most of the parameters defining tastes and technology are given standard values from the literature, as well as parameters that

credit is also introduced with a lag. 
introduce nominal and real rigidities. All coefficients for the persistence of shocks are set to 0.95. The sensitivity of the results to some of the parameters relating to non-standard aspects of the model-such as the endogeneity of lending rates-is evaluated later.

Two aspects of the model's steady state are particularly important for the results. First, we assume that debt is an important component for financing the purchase of houses- the steady-state loan-to-value ratio is 80 percent. Second, the share of residential investment in GDP is calibrated to 10 percent, which is higher than for most countries, but accurately reflects the typical share of residential investment in the sum of consumption and residential investment (which is the definition of GDP in this model). Together, these shares create a significant role for housing in economic fluctuations.

\section{Simulation Results}

The behavior of the model economy is examined under different policy regimes, following shocks that produce sustained rises in residential investment and house prices. The objective is to determine which policy regime is better at stabilizing the economy in the face pressures on the housing market-in other words, we look for policies that can help prevent financial vulnerabilities, rather than policies that help pick up the pieces after a bust. The conclusions that can be drawn from this analysis depend crucially on which shocks drive the housing boom. To illustrate the importance of correctly identifying the drivers of the housing boom, we test the policy regimes with two shocks: a financial shock that prompts a relaxation in lending standards, and a positive productivity shock. Although asset booms can arise from changes in expectations of capital gains without any change in fundamentals, we do not model "bubbles" or "irrational exuberance." Similarly, we do not attempt to model events that trigger house price crashes.

\section{A. The Performance of Policy Rules in Reaction to Financial Shocks}

Figure 1 shows the responses to a financial shock $\left(v_{t}\right)$, modeled as a relaxation in lending standards that immediately reduces lending rates by 100 basis points in the baseline Taylor regime (dotted line). Four paths are shown, corresponding to the four different policy regimes discussed above. In the baseline case, monetary policy is guided by the simple Taylor rule, and, with no macroprudential reaction, the financial shock causes an immediate increase in residential investment and house prices. Because banks are assumed to lower lending rates when collateral rises, the shock feeds on itself: housing demand raises house prices, collateral values increase, lending rates are lowered, and households take out more loans. This is the credit accelerator mechanism at work. In addition, lower rates also lead to higher demand for 
nondurable consumption goods, pushing up CPI inflation. Some of the characteristics of a house price bust are evident in the aftermath of this shock: as financial conditions normalize, residential investment - and with it, house prices - must undershoot for a period to bring the housing stock back to equilibrium. This process spills over to the rest of the economy, causing a temporary recession and raising volatility in all markets. The reaction of a central bank following a simple Taylor rule is straightforward: to the extent that the output gap and CPI inflation are positive following the increase in housing demand, policy rates are raised. Eventually, output and inflation stabilize.

Next we consider the augmented Taylor rule, which prompts the central bank to react directly to credit, in addition to the output gap and inflation. For illustration, we assume that the central bank puts the same weight $(0.5)$ on changes in nominal credit growth as on the output gap (see Table 2, second row). This rule produces greater stability across the board, as can be seen from the figure: the volatility of residential investment is lower, there is a considerable reduction in the volatility of GDP and the output gap, and house price and CPI inflation are less volatile (see also the standard deviations in Table 3, second row, compared with those in the first row).

Note that the volatility of interest rates is lower as well, even though the policy rule is more aggressive. This is because a model with fully forward-looking private agents, such as this one, has very strong expectational effects-households anticipate a stronger reaction from the central bank and factor it into their decision-making. The result is that monetary policy works through the threat of a stronger reaction, rather than by actually delivering that stronger reaction.

Macroeconomic stabilization is even better served under the third regime, under which the central bank complements the augmented rule with the use of the macroprudential instrument (Table 3, third row). For illustration, the growth rate of nominal credit in the macroprudential rule has a weight of 0.5 , with the other weights maintained as for the augmented Taylor rule. The macroprudential rule allows policymakers to directly counter the easing of lending conditions that induces borrowers to take on more debt as house prices rise.

To summarize, adding another indicator to the monetary policy reaction function and another policy instrument can improve macroeconomic stability when the economy is hit by a financial shock. The responses hint that policy reactions guided by the standard Taylor rule are too weak in the face of loosened lending standards and credit accelerator effects, with the consequence that housing investment is insufficiently dampened. But the parameters in the augmented and macroprudential rules used here are ad hoc. In fact, if the objective is simply to stabilize the output gap and inflation, the optimal weights on the output gap and inflation in monetary policy rules in these sorts of "microfounded" models are generally much higher 
than the Taylor weights. ${ }^{11}$ This implies that the improvement in stability from adding nominal credit to the monetary policy rule and employing the macroprudential instrument could simply indicate that, under the baseline Taylor rule, the reaction to the output gap and inflation is insufficient.

To address this issue, we also show the responses using the augmented Taylor and macroprudential rules optimized to minimize the variation in the output gap and in inflation. As expected, the optimized rules are the most successful in stabilizing the economy and come close to producing the efficient reaction-no output gap at all. ${ }^{12}$ More interesting are the optimized weights (Table 2, fourth row). Optimal monetary policy is very aggressive- the weights on the output gap and inflation are multiples of those in the standard Taylor rule and typical estimated monetary reaction functions, and the optimized interest rate smoothing is zero. ${ }^{13}$ The weight on nominal credit in setting the policy rate is zero. Crucially, however, the optimal weight on nominal credit in the macroprudential rule is not zero; in fact, it is slightly more than the weight used before (0.8). Hence, macroprudential policy is unambiguously useful for dealing with financial shocks, even when the central bank is free to use policy rates very aggressively. Using the macroprudential tool is a more efficient reaction to loosening credit markets than simply raising policy rates, because it tackles the problem at its root.

\section{B. The Performance of Policy Rules in Reaction to Productivity Shocks}

Broader and more aggressive policy regimes can improve stability in the face of financial shocks, but they raise the possibility of policy mistakes in the face of other types of shocks. This can be seen from the second set of simulations, which shows reactions to an increase in productivity in the nondurable goods sector that, in the case of the Taylor rule, delivers an immediate 1 percent increase in output (Figure 2). ${ }^{14}$ This results of this shock also resemble a housing boom: residential investment, house prices and the demand for credit all rise, just as in the case of a financial shock. However, the prices of consumption goods fall. Indeed, the

\footnotetext{
${ }^{11}$ See Woodford (2001) for discussion.

${ }^{12}$ The efficient reaction is desirable from a welfare point of view, but not possible in this model because of nominal rigidities and distortions in financial markets, and because we restrict our attention to backward looking Taylor rules.

${ }^{13}$ One reason for these high weights is that the only concern in the optimization procedure is minimizing the output gap and deviations in inflation, on the assumption that the economy is perfectly understood and the data have no measurement error. Introducing uncertainty can be used to motivate both more and less aggressive policy reactions, but is generally interpreted by policy makers as justifying caution.

${ }^{14}$ Although the shock is centered on the production of nondurable consumption goods, households spend more on residential investment as well as nondurables consumption because of expectations of higher income.
} 
fact that CPI inflation was contained in recent years while asset prices surged led many policy makers to conclude that asset price rises were being driven by positive productivity shocks.

The best policy for dealing with a productivity shock is for the central bank to accommodate the improvement in productivity as much as possible. The optimized regime has higher weights on the output gap and inflation, as before, but the model does not support using the macroprudential tool at all (Table 4, fourth row). Policies to suppress private sector borrowing would be misguided, as shown in the figure: following the augmented Taylor and macroprudential rules, with the same parameter values as for the financial shock, accentuates downward pressure on prices (CPI), because of the extra reaction to credit growth. The result is that the output gap and inflation are more volatile, not less (Table 5, second and third rows). Among the first three policy regimes-Taylor, augmented Taylor, augmented Taylor with macroprudential — the best is the standard Taylor rule. These results suggest that policy reactions to indicators of potential financial vulnerability should be neither automatic nor rigid-policy makers need room for discretion.

\section{Policy Rules with Multiple Shocks}

In the real world, economies are affected by multiple shocks of various types. Optimal policy rules must strike a balance among the optimal responses to each different type of shock, and must reflect the relative importance of the shocks in driving the economy. Consequently, the case for using a macroprudential tool will depend, among other things, on the mixture of shocks facing a particular economy. Figure 3 shows how the optimal weight on changes in nominal credit in the macroprudential rule rises as financial shocks become relatively more important than productivity shocks. The exercise involves specifying a sequence of variance-covariance matrices in which the ratio of the variance of the financial shock increases, while the variance of the productivity shock and the covariance of the two shocks stay fixed at one and zero, respectively, then optimizing the weights for all variables in the augmented Taylor and macroprudential rule regime for each of the variance-covariance matrices in the sequence. When there are no financial shocks, there is no need for the macroprudential tool. When there are only financial shocks, the optimal weight on nominal credit in the macroprudential rule in this model is 0.8 , as shown above. Ideally, then, policymakers would be able to use discretion to deal appropriately with different types of shocks as they arise, rather than reacting rigidly with fixed rules. 


\section{Robustness of the Results}

This question arises as to whether the results hold for alternative calibrations of the model. In this section, the augmented Taylor plus macroprudential regime is re-optimized for five alternative calibrations for which, in each case, a single parameter is changed. We concentrate on those parameters that relate to the non-standard aspects of the model, to make sure that the results are robust to reasonable variations in these parameters. ${ }^{15}$

Several authors have suggested that housing prices are fully flexible, or at least more flexible than nondurable goods (see the discussion in Iacoviello and Neri, 2009). The first variation eliminates nominal house price rigidities, by setting $\theta^{d}$ and $\phi^{d}$ to zero. The second and third test the sensitivity of the results to changes in the elasticity of the lending rate to changes in housing collateral, which was not estimated but imposed at $\kappa=0.5$ in the base calibration, by setting a lower value $(\kappa=0.1)$ and then using a substantially higher value $(\kappa=2)$. The fourth variation examines the results of using a higher value for the Frisch elasticity of labor supply, $\phi=2$, instead of the baseline calibration of $\phi=1$. Changes in this elasticity have an important impact on real unit labor costs and inflation dynamics. Finally, we look at the results when there are no labor reallocation costs $\left(\iota_{L}\right)$, which makes the model closer to a standard single-sector model.

Table 6 shows the results of the augmented Taylor plus macroprudential regimes optimized for the financial shock. Although there is a large range of values for the optimal weights on inflation and the output gap, the striking result is that the weight on nominal credit in the macroprudential rule is within the range of 0.5 to 1 . Hence, the previous result that there is an unambiguous role for the macroprudential instrument in improving macroeconomic stability holds under reasonable variations of parameter values.

The table also shows that the weight on nominal credit in the monetary policy rule is uniformly zero, while the weights on inflation are consistently higher than 1.5 as in the standard Taylor rule. This is consistent with the previous result that there is no distinct indicator value for nominal credit in the monetary policy rule, but only as long as monetary policy is free to react more strongly in dampening the shock than is conventionally imposed in standard Taylor rules or estimated.

Table 7 shows the results when the regime is optimized for the productivity shock. As with the baseline calibration, there is no role for macroprudential policy in addressing this shock, with the single exception of the calibration with fully-flexible house prices. Similarly, there is optimally a stronger weight put on inflation and, in particular, the output gap. The weight on

\footnotetext{
${ }^{15}$ Using a different model, Chadha et al. (2009) report qualitatively similar results for the benefits of using an indicator of credit market conditions in the optimal simple rule.
} 
nominal credit is consistently low and sometimes zero. Hence, the previous result that inflexible use of rigid macroprudential rules could sometimes result in policy errors is reinforced.

\section{Conclusions}

Monetary policy makers in advanced economies with flexible exchange rate regimes have been guided in recent years by the principle that stabilizing inflation forms the best policy for promoting economic growth and welfare. Moreover, it was suggested that stable inflation would reduce risk premia and increase financial stability. Thus, a number of central banks have been given explicit mandates to target CPI inflation, and they have been strikingly successful in achieving this objective. But this approach has not been enough to prevent asset price busts.

The results from the simulations show that there are potential benefits from aggressive monetary policy reactions to financial shocks that would otherwise generate a cycle of loosening credit conditions, overvalued housing, and over-extended households. In addition, macroprudential tools could be used to help tackle loose financial conditions. The simulations also clearly show the importance of being able to identify the shocks that are driving changes in financial conditions and asset prices-in the case of a productivity shock, the best monetary policy is to accommodate the shock as much as possible, and there is no role for a macroprudential tool.

However, the simulations in this section are very stylized, and many potentially important factors are omitted. The model captures some relevant features of the world, but has not been fitted to any particular economy. An important empirical issue is how important financial shocks are relative to others, such as productivity shocks.

Going forward, the best case is for policymakers to be given extra tools with which to address financial shocks. Such tools might reduce the need for aggressive monetary policy reactions and should, in principle, be less disruptive to the whole macroeconomy than using policy rates. However, the characterization of the macroprudential tools in the model used in this paper is very simple and glosses over important questions about how exactly such tools would be managed and how effective they could be in actual financial systems. Hence, the results are only suggestive, and further research on the practicalities of such tools is required.

Although the optimal rules for reacting to financial shocks have zero weight on nominal credit, the large weights on inflation and output are much larger than those found in estimated simple rules based on actual central bank behavior. In practice, it might prove difficult to justify such strong reactions, especially if inflation pressures are moderate and the immediate 
result would be to lower consumption and employment. Hence, another possibility is that central bank mandates be expanded to include explicit concern for avoiding financial vulnerabilities. As with macroprudential instruments, there are some significant practical issues that will need to be carefully assessed before a broader framework for monetary policy is implemented, and expectations about what can be achieved must be realistic. Rigid reactions to indicators such as nominal credit flows and inflexible use of policy tools will likely lead to policy mistakes, so judgment and discretion is required. Hence, implementing a broader framework for monetary policy to mitigate macrofinancial risks would further increase the importance of correctly identifying the sources of shocks driving changes credit and asset prices. Central bankers implementing broader policies would need to explain very carefully the basis for their actions, their immediate objectives, and how their actions are consistent with longer-term objectives of price stability. Moreover, monetary and macroprudential policies would need to be coordinated, requiring greater information exchange and more consultation between monetary and supervisory authorities. 


\section{References}

Aoki, Kosuke, James Proudman, and Gertjan Vlieghe, 2004, "House Prices, Consumption, and Monetary Policy: A Financial Accelerator Approach," Journal of Financial Intermediation, Vol. 13, No. 4, pp. 414-35.

Bernanke, Ben, Mark Gertler, and Simon Gilchrist, 1998, "The Financial Accelerator in a Quantitative Business Cycle Framework," NBER Working Paper No. 6455 (Cambridge, Massachusetts: National Bureau of Economic Research).

Bernanke, Ben, and Mark Gertler, 2001, "Should Central Banks Respond to Movements in Asset Prices?” American Economic Review Vol. 91, No. 2, pp.253-257.

Borio, Claudio, and Philip Lowe, 2004, "Securing Sustainable Price Stability: Should Credit Come Back from the Wilderness?" BIS Working Paper No. 157 (Basel: Bank for International Settlements).

Calvo, Guillermo, 1983, "Staggered Prices in a Utility-maximizing Framework," Journal of Monetary Economics, Vol. 12, Issue 3, pp. 383-398.

Cecchetti, Stephen G., Hans Genberg, John Lipsky and Sushil Wadhwani, 2000, Asset Prices and Central Bank Policy, Geneva Reports on the World Economy 2 (Geneva: International Centre for Monetary and Banking Studies).

Chadha, Jagjit S., Luisa Corrado, and Sean Holly, 2009, "Reconnecting 'Money' to Inflation: the Pivotal Role of the External Finance Premium," (unpublished; University of Kent).

Christiano, Lawrence, Martin Eichenbaum, and Charles Evans, 2005, "Nominal Rigidities and the Dynamic Effects of a Shock to Monetary Policy," Journal of Political Economy, Vol. 113, Issue 1, pp. 1-45.

Christiano, Lawrence J., Roberto Motto, and Massimo Rostagno, 2007, “Two Reasons Why Money and Credit May Be Useful in Monetary Policy," paper presented at the fourth ECB Central Banking Conference, "The Role of Money: Money and Monetary Policy in the Twenty-First Century," Frankfurt, November 9-10, 2006.

Cúrdia, Vasco, and Michael Woodford, 2009, "Credit Spreads and Monetary policy," NBER Working Paper 15289.

Galí, Jordi, 2009, Monetary Policy, Inflation, and the Business Cycle, Princeton University Press.

Gray, Dale, Carlos García, Leonardo Luna, and Jorge E. Restrepo, forthcoming, "Incorporating Financial Sector Risk into Monetary Policy Models: Application to Chile,” IMF Working 
Paper (Washington: International Monetary Fund).

Gruss, Bertrand, and Silvia Sgherri, 2009, “The Volatility Costs of Procyclical Lending Standards: An Assessment Using a DSGE Model,’ IMF Working Paper No. 09/35 (Washington: International Monetary Fund).

Iacoviello, Matteo, 2005, "House Prices, Borrowing Constraints, and Monetary policy in the Business Cycle," American Economic Review, Vol. 95, No. 3, pp. 739-64.

Iacoviello, Matteo, and Stefano Neri, 2009, "Housing Market Spillovers: Evidence from an Estimated DSGE Model", AEJ Macro, forthcoming.

International Monetary Fund, 2009, "Lessons from Asset Price Fluctuations for Monetary Policy," Chapter 3 of World Economic Outlook, Washington, DC: International Monetary Fund.

Kannan, Prakash, Pau Rabanal and Alasdair Scott, 2009, "Macroeconomic Patterns in the Lead-up to Asset Price Busts," IMF Working Paper, forthcoming.

Monacelli, Tommaso, 2009, “New Keynesian Models, Durable Goods, and Collateral,' Journal of Monetary Economics, Vol. 56, pp. 242-54.

Woodford, Michael, 2001, "The Taylor Rule and Optimal Monetary Policy” (unpublished; Princeton, New Jersey: Princeton University). 
Table 1: Parameter values

\begin{tabular}{|l|l|l|}
\hline Parameter & Description & Value \\
\hline$\beta$ & Discount factor savers & 0.99 \\
\hline$\beta^{B}$ & Discount factor borrowers & 0.98 \\
\hline$\delta$ & Depreciation rate & 0.025 \\
\hline$\lambda$ & Share of savers & $1 / 2$ \\
\hline$\chi$ & Down payment rate (1 minus LTV) & 0.2 \\
\hline$\sigma /(\sigma-1)$ & Average markup & 1.1 \\
\hline$\iota_{L}$ & Labor disutility of switching sectors & 1 \\
\hline$\varphi$ & Inverse Frisch elasticity of labor supply & 1 \\
\hline$\varepsilon$ & Habit formation & 0.75 \\
\hline$\eta$ & Adjustment cost residential investment & 0.5 \\
\hline$\kappa$ & Elasticity of spread with respect to net worth & 0.5 \\
\hline$\alpha$ & Share of nondurables in GDP & 0.9 \\
\hline$\theta_{c}$ & Calvo lottery nondurable & 0.75 \\
\hline$\theta_{d}$ & Calvo lottery durable & 0.66 \\
\hline$\phi_{c}$ & Backward looking behavior nondurable & 1 \\
\hline$\phi_{d}$ & Backward looking behavior durable & 1 \\
\hline
\end{tabular}


Table 2: Parameters of policy rules in reaction to financial shocks

\begin{tabular}{|l|c|c|c|c|c|}
\hline & $\gamma_{r}$ & $\gamma_{\pi}$ & $\gamma_{y}$ & $\gamma_{b}$ & $\tau$ \\
\hline Taylor & 0.7 & 1.5 & 0.5 & - & - \\
\hline Augmented Taylor & 0.7 & 1.5 & 0.5 & 0.5 & - \\
\hline Augmented Taylor + macroprudential & 0.7 & 1.5 & 0.5 & 0.5 & 0.5 \\
\hline Optimized augmented Taylor + macroprudential & 0.0 & 13.2 & 3.2 & 0.0 & 0.8 \\
\hline
\end{tabular}


Table 3: Performance of policy rules in reaction to financial shocks

\begin{tabular}{|l|c|c|c|c|}
\hline & Std. dev. CPI inflation & Std. dev. output gap & Loss & Rank \\
\hline Taylor & 0.512 & 0.624 & 0.652 & 4 \\
\hline Augmented Taylor & 0.110 & 0.076 & 0.018 & 3 \\
\hline $\begin{array}{l}\text { Augmented Taylor } \\
\text { + macroprudential }\end{array}$ & 0.092 & 0.061 & 0.012 & 2 \\
\hline $\begin{array}{l}\text { Optimized augmented Taylor } \\
\text { + macroprudential }\end{array}$ & 0.018 & 0.040 & 0.002 & 1 \\
\hline
\end{tabular}

Loss equals sum of the variances of CPI inflation and output gap. 
Table 4: Parameters of policy rules in reaction to productivity shocks

\begin{tabular}{|l|c|c|c|c|c|}
\hline & $\gamma_{r}$ & $\gamma_{\pi}$ & $\gamma_{y}$ & $\gamma_{b}$ & $\tau$ \\
\hline Taylor & 0.7 & 1.5 & 0.5 & - & - \\
\hline Augmented Taylor & 0.7 & 1.5 & 0.5 & 0.5 & - \\
\hline Augmented Taylor + macroprudential & 0.7 & 1.5 & 0.5 & 0.5 & 0.5 \\
\hline Optimized augmented Taylor + macroprudential & 0.0 & 3.5 & 12.0 & 0.3 & 0.0 \\
\hline
\end{tabular}


Table 5: Performance of policy rules in reaction to productivity shocks

\begin{tabular}{|l|c|c|c|c|}
\hline & Std. dev. CPI inflation & Std. dev. output gap & Loss & Rank \\
\hline Taylor & 0.199 & 0.162 & 0.066 & 2 \\
\hline Augmented Taylor & 0.184 & 0.220 & 0.082 & 3 \\
\hline $\begin{array}{l}\text { Augmented Taylor } \\
\text { + macroprudential }\end{array}$ & 0.233 & 0.276 & 0.130 & 4 \\
\hline $\begin{array}{l}\text { Optimized augmented Taylor } \\
\text { + macroprudential }\end{array}$ & 0.072 & 0.080 & 0.011 & 1 \\
\hline
\end{tabular}

Loss equals sum of the variances of CPI inflation and output gap. 
Table 6: Sensitivity of parameters of policy rules optimized to financial shocks to changes in key parameters

\begin{tabular}{|l|r|r|r|c|c|}
\hline & $\gamma_{r}$ & \multicolumn{1}{|c|}{$\gamma_{\pi}$} & \multicolumn{1}{c|}{$\gamma_{y}$} & $\gamma_{b}$ & $\tau$ \\
\hline Original calibration & 0.0 & 13.2 & 3.2 & 0.0 & 0.80 \\
\hline Flexible house prices $\left(\theta^{d}=0, \phi^{d}=0\right)$ & 0.0 & 14.3 & 1.6 & 0.0 & 0.75 \\
\hline Lower lending rate elasticity $(\kappa=0.1)$ & 0.0 & 9.1 & 0.8 & 0.0 & 0.85 \\
\hline Higher lending rate elasticity $(\kappa=2)$ & 0.0 & 18.0 & 12.4 & 0.0 & 0.55 \\
\hline Higher labor elasticity $(\phi=2)$ & 0.0 & 15.9 & 0.0 & 0.0 & 0.90 \\
\hline No labor reallocation costs $\left(\iota^{L}=0\right)$ & 0.0 & 11.8 & 4.0 & 0.0 & 1.00 \\
\hline
\end{tabular}


Table 7: Sensitivity of parameters of policy rules optimized to productivity shocks to changes in key parameters

\begin{tabular}{|l|r|r|r|c|c|}
\hline & $\gamma_{r}$ & \multicolumn{1}{|c|}{$\gamma_{\pi}$} & \multicolumn{1}{c|}{$\gamma_{y}$} & $\gamma_{b}$ & $\tau$ \\
\hline Original calibration & 0.0 & 3.5 & 12.0 & 0.3 & 0.00 \\
\hline Flexible house prices $\left(\theta^{d}=0, \phi^{d}=0\right)$ & 0.0 & 11.8 & 21.6 & 0.0 & 0.60 \\
\hline Lower lending rate elasticity $(\kappa=0.1)$ & 0.0 & 5.5 & 20.8 & 0.5 & 0.00 \\
\hline Higher lending rate elasticity $(\kappa=2)$ & 0.0 & 3.1 & 8.0 & 0.3 & 0.00 \\
\hline Higher labor elasticity $(\phi=2)$ & 0.0 & 2.7 & 7.8 & 0.0 & 0.00 \\
\hline No labor reallocation costs $\left(\iota^{L}=0\right)$ & 0.0 & 2.2 & 4.4 & 0.2 & 0.00 \\
\hline
\end{tabular}


Figure 1. Effect of a Financial Shock

(Deviation from steady state; quarters on $x$-axis)

The figure shows impulse response to an unanticipated financial shock in the first quarter. The size of the shock is normalized such that it leads to a 1 percent decline of the lending rate on impact under the Taylor rule. Paths denote different policy regimes.

$$
\begin{array}{lll}
\text {........ Taylor } & \text { Augmented Taylor + macroprudential } \\
\text {.... Augmented Taylor } \quad \text { Optimized Augmented Taylor + macroprudential }
\end{array}
$$
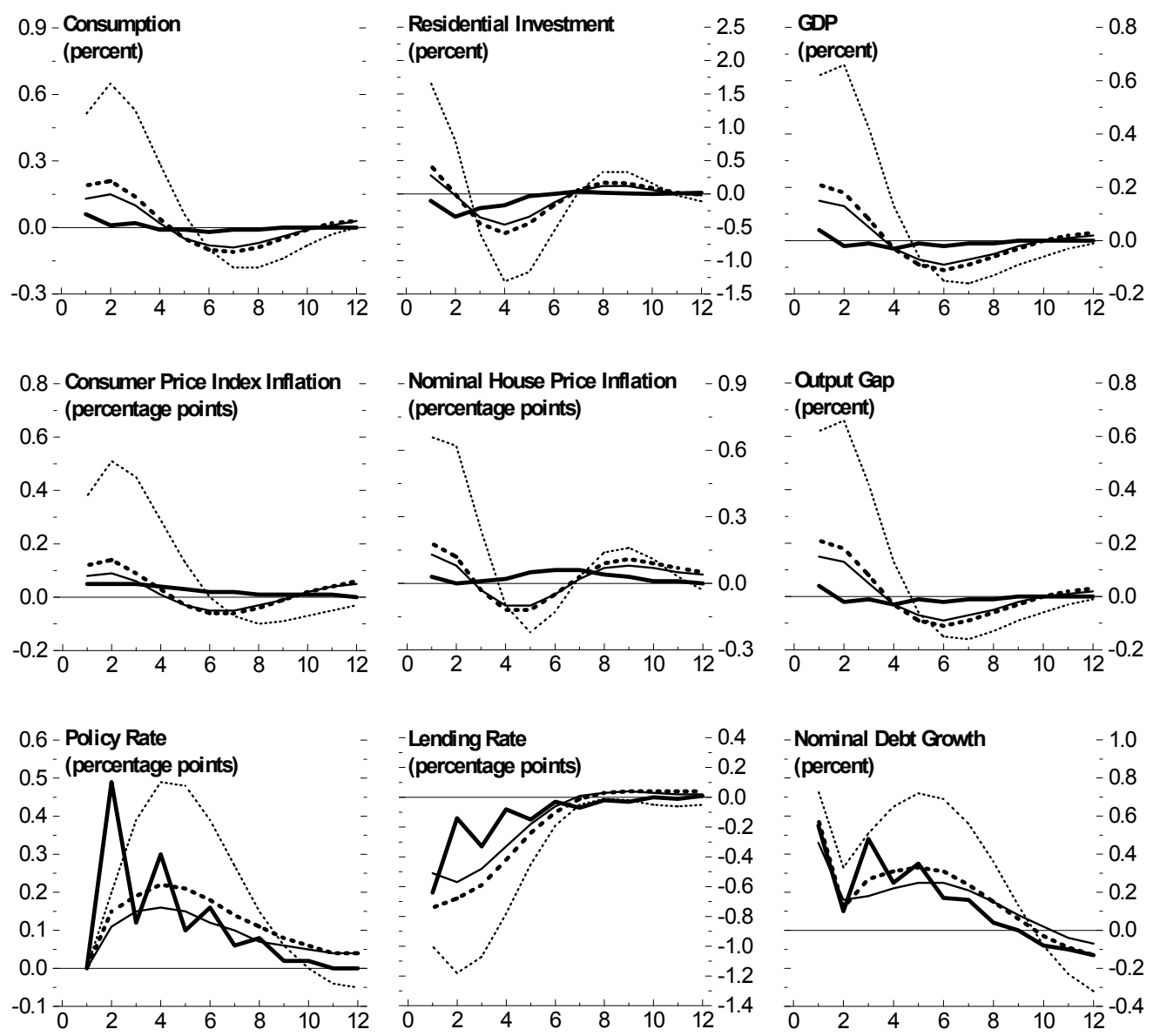

Source: IMF staff calculations. 


\section{Figure 2. Effect of a Productivity Shock}

(Deviation from steady state; quarters on $x$-axis)

The figure shows impulse response to an unanticipated productivity shock in the first quarter. The size of the shock is normalized such that it leads to a 1 percent increase in real GDP on impact under the Taylor rule. Paths denote different policy regimes.

$$
\begin{array}{ll}
\text {........ Taylor } & \text { Augmented Taylor + macroprudential } \\
\text {..... Augmented Taylor } \quad \text { Optimized Augmented Taylor + macroprudential }
\end{array}
$$
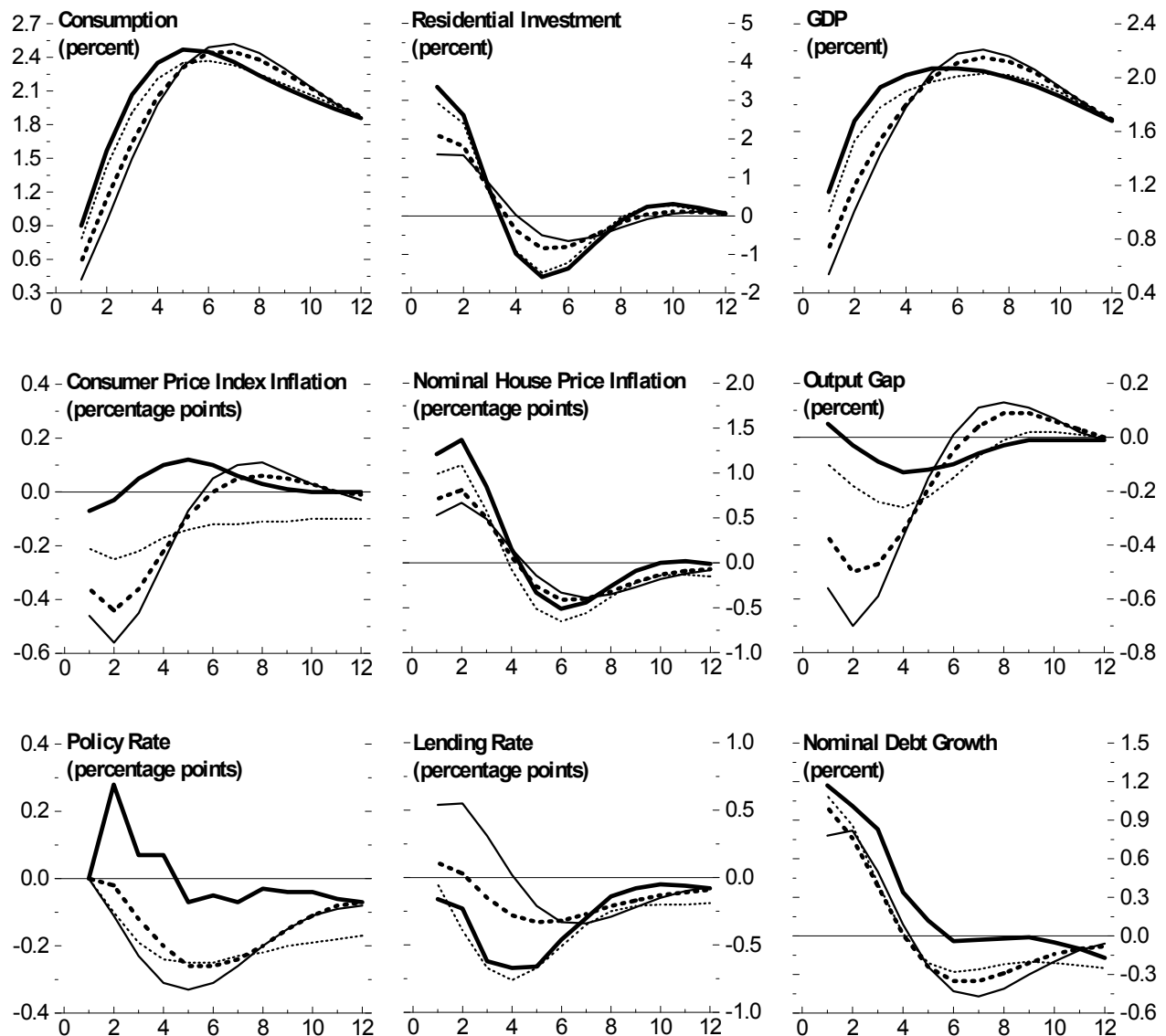

Nominal House Price Inflation - 2.0 (percentage points)
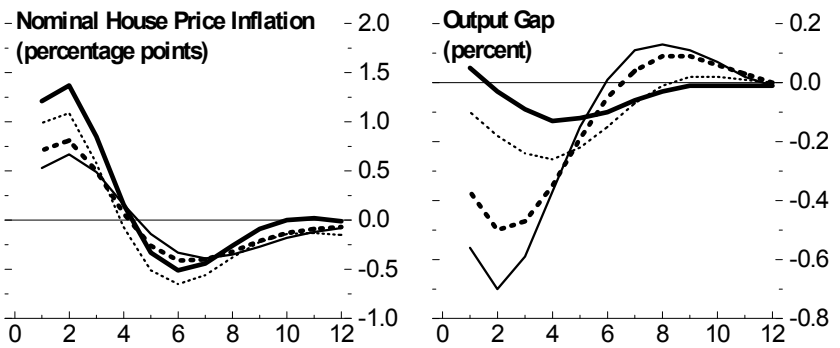

-Lending Rate

( (percentage points)
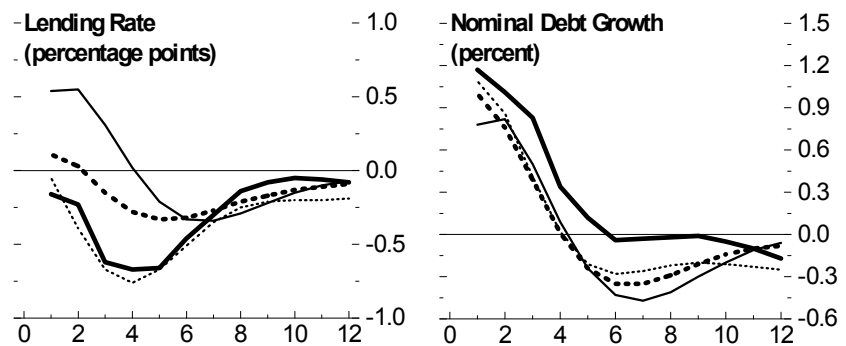

Source: IMF staff calculations. 


\section{Figure 3. Optimal Weight on Nominal Credit in the Macroprudential Rule}

As the importance of financial shocks increases, the macroprudential tool becomes more useful.

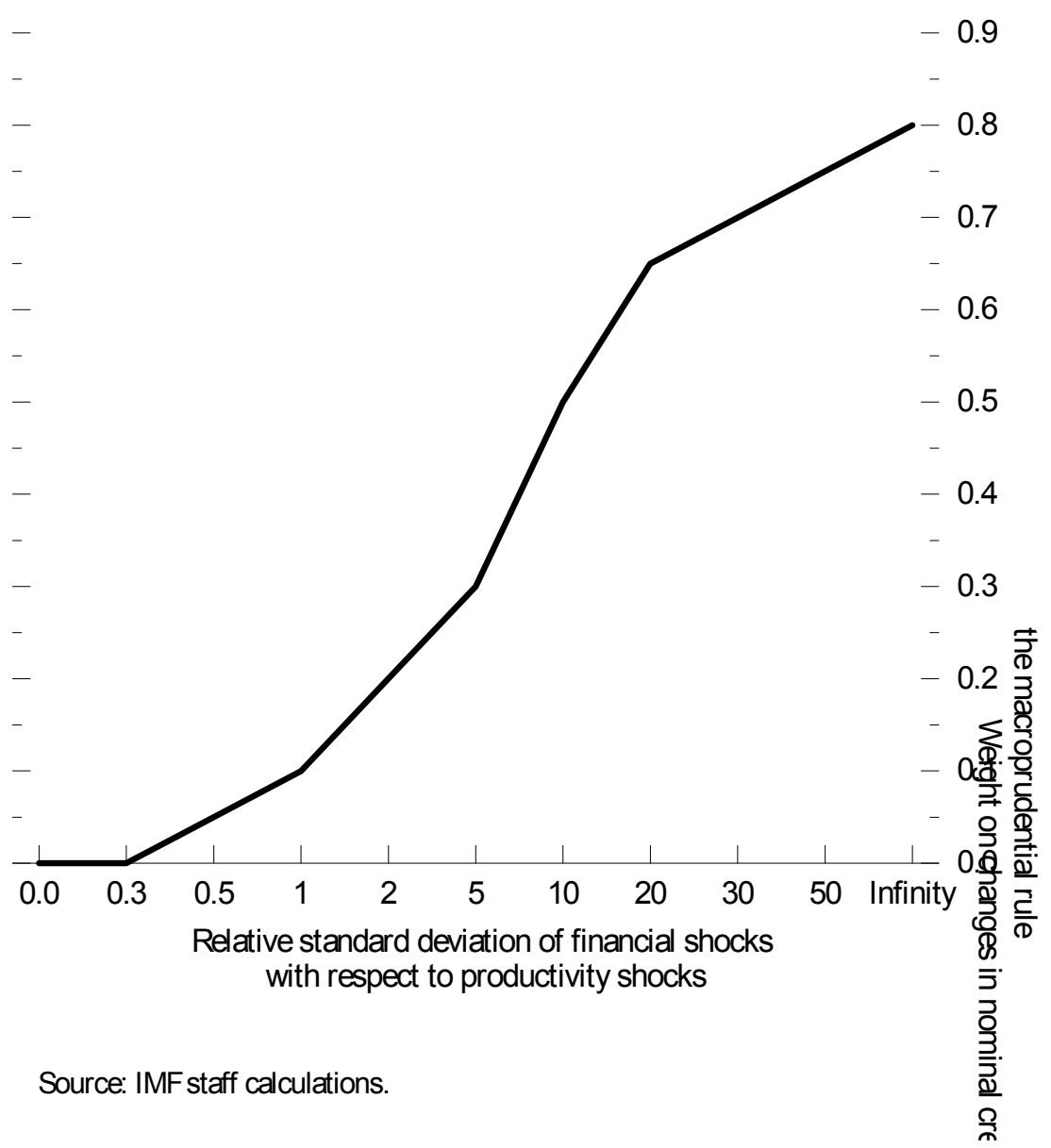




\section{Appendix: Linearized Conditions}

This appendix provides the log-linear conditions. Lower case variables denote log-linear deviations from steady-state values. Also, we define the relative price of durables in terms of non-durables as $Q_{t}=\frac{P_{t}^{D}}{P_{t}^{C}}$. Also, $\omega_{t}^{i}$ denotes deviations from the real wage from steady-state values, defined as nominal wage $\left(W_{t}^{i}\right)$ divided by the aggregate price level $\left(P_{t}\right)$, for $i=C, D$.

From the optimal decisions by savers we get the following:

$$
q_{t}-\frac{c_{t}-\varepsilon c_{t-1}}{1-\varepsilon}+\eta\left(i_{t}-i_{t-1}\right)=\mu_{t}+\beta \eta\left(E_{t} i_{t+1}-i_{t}\right)
$$

where $\eta=\bar{S}^{\prime \prime}($.

$$
\begin{gathered}
{[1-\beta(1-\delta)]\left(\xi_{t}^{D}-d_{t}\right)=\mu_{t}-\beta(1-\delta) E_{t} \mu_{t+1}} \\
\varepsilon \Delta c_{t}=E_{t} \Delta c_{t+1}-(1-\varepsilon)\left(r_{t}-E_{t} \Delta p_{t+1}^{C}\right) \\
\frac{c_{t}-\varepsilon c_{t-1}}{1-\varepsilon}+\left[\left(\varphi-\iota_{L}\right) \alpha+\iota_{L}\right] l_{t}^{C}+\left(\varphi-\iota_{L}\right)(1-\alpha) l_{t}^{D}=\omega_{t}^{C}+(1-\gamma) q_{t} \\
\frac{c_{t}-\varepsilon c_{t-1}}{1-\varepsilon}+\left[\left(\varphi-\iota_{L}\right)(1-\alpha)+\iota_{L}\right] l_{t}^{D}+\left(\varphi-\iota_{L}\right) \alpha l_{t}^{C}=\omega_{t}^{D}+(1-\gamma) q_{t}
\end{gathered}
$$

The same conditions for borrowers are:

$$
\begin{gathered}
q_{t}-\frac{c_{t}^{B}-\varepsilon c_{t-1}^{B}}{1-\varepsilon}+\eta\left(i_{t}^{B}-i_{t-1}^{B}\right)=\mu_{t}^{B}+\beta^{B} \eta\left(E_{t} i_{t+1}^{B}-i_{t}^{B}\right) \\
{\left[1-\beta^{B}(1-\delta)\right]\left(\xi_{t}^{D}-d_{t}^{B}\right)=\mu_{t}^{B}-\beta^{B}(1-\delta) E_{t} \mu_{t+1}^{B}} \\
\varepsilon \Delta c_{t}^{B}=E_{t} \Delta c_{t+1}^{B}-(1-\varepsilon)\left(r_{t}^{L}-E_{t} \Delta p_{t+1}^{C}\right) \\
\frac{c_{t}^{B}-\varepsilon c_{t-1}^{B}}{1-\varepsilon}+\left[\left(\varphi-\iota_{L}\right) \alpha+\iota_{L}\right] l_{t}^{B, C}+\left(\varphi-\iota_{L}\right)(1-\alpha) l_{t}^{B, D}=\omega_{t}^{C}+(1-\gamma) q_{t} \\
\frac{c_{t}^{B}-\varepsilon c_{t-1}^{B}}{1-\varepsilon}+\left[\left(\varphi-\iota_{L}\right)(1-\alpha)+\iota_{L}\right] l_{t}^{B, D}+\left(\varphi-\iota_{L}\right) \alpha l_{t}^{B, C}=\omega_{t}^{D}+(1-\gamma) q_{t}
\end{gathered}
$$

The budget constraint of impatient households is:

$$
\begin{aligned}
& C^{B}\left[c_{t}^{B}-(1-\gamma) q_{t}\right]+I^{B}\left(\gamma q_{t}+i_{t}^{B}\right)+R^{L} B^{B}\left(r_{t-1}^{L}+b_{t-1}^{B}-\Delta p_{t}\right) \\
= & B^{B} b_{t}^{B}+\alpha W L^{B}\left(\omega_{t}^{C}+l_{t}^{C, B}\right)+(1-\alpha) W L^{B}\left(\omega_{t}^{D}+l_{t}^{D, B}\right)
\end{aligned}
$$


where $b_{t}^{B}$ is the deviation of the real value of credit from its steady-state value (i.e. deviations of $B_{t}^{B} / P_{t}$ from its steady-state value). The effective interest rate for borrowers is a spread over the riskless rate, with an exogenous markup shock $\left(v_{t}\right)$ and an endogenous component, that depends on the loan-to-value ratio for borrowers in the economy:

$$
r_{t}^{L}=r_{t}+\kappa\left(b_{t}^{B}-d_{t}^{B}-\gamma q_{t}-v_{t}\right)+\tau\left(b_{t-1}^{B}-b_{t-2}^{B}+\Delta p_{t-1}\right)
$$

where we have substituted the macro-prudential rule. As long as $\tau=0$ this instrument is not operational, otherwise it raises the costs of lending in proportion to nominal credit growth.

The aggregate price index (or GDP deflator) is a combination of CPI inflation and nominal house price inflation:

$$
\Delta p_{t}=\gamma \Delta p_{t}^{C}+(1-\gamma) \Delta p_{t}^{D}
$$

and the relative price of housing is:

$$
q_{t}=q_{t-1}+\Delta p_{t}^{D}-\Delta p_{t}^{C}
$$

The production functions are given by:

$$
\begin{aligned}
& y_{t}^{C}=a_{t}^{C}+l_{t}^{C, t o t} \\
& y_{t}^{D}=a_{t}^{D}+l_{t}^{D, t o t}
\end{aligned}
$$

And the pricing equations are given by

$$
\Delta p_{t}^{C}-\varphi_{C} \Delta p_{t-1}^{C}=\beta E_{t}\left(\Delta p_{t+1}^{C}-\varphi_{C} \Delta p_{t}^{C}\right)+\kappa^{C}\left[\omega_{t}^{C}+(1-\gamma) q_{t}-a_{t}^{C}\right]
$$

where $\kappa^{C}=\frac{\left(1-\theta_{C}\right)\left(1-\beta \theta_{C}\right)}{\theta_{C}}$.

$$
\Delta p_{t}^{D}-\varphi_{D} \Delta p_{t-1}^{D}=\beta E_{t}\left(\Delta p_{t+1}^{D}-\varphi_{D} \Delta p_{t}^{D}\right)+\kappa^{D}\left[\omega_{t}^{D}-\gamma q_{t}-a_{t}^{D}\right]
$$

where $\kappa^{D}=\frac{\left(1-\theta_{D}\right)\left(1-\beta \theta_{D}\right)}{\theta_{D}}$.

The market clearing conditions for the nondurable goods sectors read as follows:

$$
y_{t}^{C}=\frac{\lambda C c_{t}+(1-\lambda) C^{B} c_{t}^{B}}{\left[\lambda C+(1-\lambda) C^{B}\right]}
$$

Aggregate investment expenditures equal production of investment goods:

$$
y_{t}^{D}=\frac{\lambda \delta D i_{t}+(1-\lambda) \delta D^{B} i_{t}^{B}}{\lambda \delta D+(1-\lambda) \delta D^{B}}
$$


And the law of motion of the two types of housing stocks are given by:

$$
\begin{gathered}
d_{t}=(1-\delta) d_{t-1}+\delta i_{t} \\
d_{t}^{B}=(1-\delta) d_{t-1}^{B}+\delta i_{t}^{B}
\end{gathered}
$$

where hours in each sector are:

$$
\begin{aligned}
& l_{t}^{C, t o t}=\frac{\lambda L l_{t}^{C}+(1-\lambda) L^{B} l_{t}^{C, B}}{\left[\lambda L+(1-\lambda) L^{B}\right]} \\
& l_{t}^{D, t o t}=\frac{\lambda L l_{t}^{D}+(1-\lambda) L^{B} l_{t}^{D, B}}{\left[\lambda L+(1-\lambda) L^{B}\right]}
\end{aligned}
$$

To close the model, we specify a monetary policy Taylor rule:

$$
r_{t}=\gamma_{R} r_{t-1}+\left(1-\gamma_{R}\right)\left(\gamma_{\Pi} \Delta p_{t-1}^{C}+\gamma_{y}\left(y_{t-1}-y_{t-1}^{*}\right)+\gamma_{d} \Delta p_{t-1}^{D}+\gamma_{b}\left(b_{t-1}^{B}-b_{t-2}^{B}+\Delta p_{t-1}\right)\right.
$$

where aggregate real GDP equals:

$$
y_{t}=\alpha y_{t}^{C}+(1-\alpha) y_{t}^{D}
$$

While the shocks evolve as follows:

$$
\begin{aligned}
a_{t}^{C} & =\rho_{a}^{C} a_{t-1}^{C}+\varepsilon_{t}^{a, C} \\
a_{t}^{D} & =\rho_{a}^{D} a_{t-1}^{D}+\varepsilon_{t}^{a, D} \\
v_{t} & =\rho_{v} v_{t-1}+\varepsilon_{t}^{v}
\end{aligned}
$$

although in practice we only focus on TFP shocks in the nondurable sector $\left(a_{t}^{C}\right)$ and on the financial shock $\left(v_{t}\right)$. 